\title{
Correction to: Adults with Autism Tend to Underestimate the Hidden Environmental Structure: Evidence from a Visual Associative Learning Task
}

\author{
Laurie-Anne Sapey-Triomphe ${ }^{1} \cdot$ Sandrine Sonié ${ }^{1,2,3} \cdot$ Marie-Anne Hénaff $^{1} \cdot$ Jérémie Mattout $^{1} \cdot$ Christina Schmitz $^{1}$ (i)
}

Published online: 10 May 2018

○) Springer Science+Business Media, LLC, part of Springer Nature 2018

\section{Correction to: \\ Journal of Autism and Developmental Disorders \\ https://doi.org/10.1007/s10803-018-3574-1}

The original version of this article unfortunately contained a mistake in the article title.

The word "Undermine" was changed to "Underestimate" in the original article.

Jérémie Mattout and Christina Schmitz have contributed equally to this work.

The original article can be found online at https://doi.org/10.1007/ s10803-018-3574-1.

Christina Schmitz

christina.schmitz@inserm.fr

1 Lyon Neuroscience Research Center, Brain Dynamics and Cognition Team, INSERM UMRS 1028, CNRS UMR

5292, Université Claude Bernard Lyon 1, Université de Lyon, 69000 Lyon, France

2 Centre de Ressource Autisme Rhône-Alpes, Centre Hospitalier Le Vinatier, Bron, France

3 Hôpital Saint-Jean-de-Dieu, Lyon, France 